sendo mais evidente no G3. Em relação aos percentuais de tecido ósseo em formação, ocorreu diferença significante entre os períodos (14 e 42 dias) em cada um dos Grupos. Quando comparados os Grupos G1, G2 e G3, ocorreu um maior percentual de formação de novo tecido ósseo no G3, com diferença significante em relação ao G2, nos períodos de 14 dias e 42 dias. Os Grupos G1 e G2 não apresentaram diferença estatisticamente significante entre si $(\mathrm{p}<0,05)$.

Conclusões: A terapia por fotobiomodulação, com uso de laser de baixa potência, auxiliou no processo de reparo ósseo, principalmente quando associada ao Orthogen e ao biopolímero de fibrina.

http://doi.org/10.24873/j.rpemd.2018.11.323

\#088 Dentistas portugueses, cancro oral e lesões potencialmente malignas - a propósito do PIPCO

Ana Catarina Pinto*, Inês Henriques, Inês Lourenço Cardoso, Pedro Trancoso, António Mano Azul

Faculdade Ciências da Saúde Universidade Fernando Pessoa, Clínica Integrada de Medicina Oral - Departamento de Cirurgia e Medicina Oral

Objetivos: Avaliar o comportamento dos dentistas portugueses face ao cancro, lesões potencialmente malignas e Programa de Intervenção Precoce no Cancro Oral (PIPCO).

Materiais e métodos: Inquérito anónimo com 40 perguntas aplicado através de redes sociais. Foi realizada análise estatística descritiva e inferencial.

Resultados: Dos 317 inquiridos (69,6\% do género feminino, $30,4 \%$ do género masculino), 53,7\% tinham entre 23 e 34 anos e quase metade formou-se após 2011. O tabaco (99,7\%), o álcool (93,9\%), a exposição solar para o cancro do lábio (89,4 \%), o HPV $(87,8 \%)$ e as lesões potencialmente malignas $(87,8 \%)$ foram reconhecidos como fatores de risco, enquanto $70,4 \%$ referiram também o trauma. Foram reconhecidas como lesões potencialmente malignas a leucoplasia $(93,9 \%)$, eritroplasia $(73,3 \%)$ e líquen plano oral (49,5\%), enquanto $36,7 \%$ também referiram a queratose friccional. 93\% consideraram como característica clínica primária do cancro oral uma ulceração que não cicatriza. 47,9\% identificaram a língua como a localização mais frequente. $82,3 \%$ associaram o HPV aos casos de cancro oral em doentes jovens não fumadores. 40,2\% realizam exame intra-oral completo pelo menos a cada 6 meses, mas apenas 7,4\% procuram nódulos linfáticos cervicais aumentados. Nos últimos 2 anos, 61,2\% observaram pelo menos uma lesão suspeita de cancro, confirmada em $54,4 \%$ dos casos. Apenas $21 \%$ consideraram que estão aptos para realizar o diagnóstico clínico do cancro oral. Em relação ao PIPCO, 2 em cada 3 colegas conhecem o programa. Só 18 \% já o utilizaram, em situações de lesões suspeitas de cancro (31\%), potencialmente malignas (42\%) ou de diagnóstico desconhecido (27\%). Resultados completos serão apresentados e discutidos com base nos dados internacionais.

Conclusões: Em geral, nossos resultados são melhores do que a maioria dos estudos europeus, provavelmente refletindo os diversos programas de educação contínua nesta área, quer da Ordem dos Médicos Dentistas quer das sociedades cientí- ficas. Ainda assim, os dentistas portugueses sentem a necessidade de mais formação nesta área.

http://doi.org/10.24873/j.rpemd.2018.11.324

\section{\#089 Actinomyces no Prognóstico da Osteonecrose dos Maxilares Relacionada com Medicamentos}

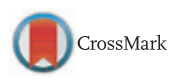

João André Correia*, José Ricardo Ferreira, Cecília Franco Caldas, Nuno Santos, António Capelo, Francisco Salvado

Serviço de Estomatologia, Centro Hospitalar Lisboa Norte

Objetivos: Descrever a prevalência de Actinomyces na amostra de doentes com Osteonecrose dos Maxilares Relacionada com Medicamentos; determinar se a presença de Actinomyces no osso necrótico é um factor relevante na fisiopatologia e prognóstico.

Materiais e métodos: Estudo restrospectivo incluindo todos os doentes com diagnóstico de Osteonecrose dos Maxilares Relacionada com Medicamentos submetidos a sequestrectomia ou ressecção marginal, no Serviço de Estomatologia do Centro Hospitalar Lisboa Norte, até Março de 2018. Um acompanhamento inferior a 3 meses foi considerado critério de exclusão. Todas as amostras de osso foram avaliadas quanto à presença de Actinomyces, através de análise histopatológica. O resultado do tratamento foi definido como Cura/Melhoria vs. Estável/Agravamento. A análise estatística foi realizada com IBM $^{\circledR}$ SPSS $^{\circledR}$ versão 23 e a significância estatística definida para valores $\mathrm{p}<0.05$.

Resultados: Foram incluídos 70 doentes na amostra, 47 do sexo feminino e 23 do sexo masculino, com uma idade média de $67,77 \pm 11,27$ anos. Identificou-se Actinomyces em 48 doentes $(68,6 \%)$. O tempo médio decorrido entre o diagnóstico e a intervenção foi de $344,94 \pm 447,33$ dias nos doentes com evidência de Actinomyces e 161,77 $\pm 198,15$ dias nos doentes sem evidência $(p<0.02)$. Estes agentes foram identificados em $41,7 \%$ dos doentes submetidos a cirurgia no primeiro mês, $69,2 \%$ entre 1 e 12 meses e 84,2\% após 12 meses. A Cura/Melhoria foi obtida em $67,9 \%$ dos pacientes positivos para Actinomyces e $70,6 \%$ dos pacientes negativos, sem significância estatística ( $\mathrm{p}<0.83)$. A análise de regressão múltipla revelou que o tempo de cura está associado significativamente com o tempo de intervenção $(p<0.01)$ mas não com a presença de Actinomyces $(\mathrm{p}<0.62)$.

Conclusões: A prevalência de Actinomyces é elevada neste grupo de doentes, tal como descrito na literatura. Encontrou-se Actinomyces em menos de metade dos doentes intervencionados no primeiro mês após o diagnóstico, o que tende a aumentar naqueles que foram operados numa fase mais tardia. Deste modo, a colonização por estes agentes oportunistas não parece desempenhar um papel essencial na patogénese da Osteonecrose dos Maxilares Relacionada com Medicamentos. Pelo contrário, poderá revelar-se uma consequência da exposição óssea prolongada. Para mais, a presença de Actinomyces não demonstrou influenciar o resultado do tratamento e, como tal, não deverá ser considerado factor de prognóstico.

http://doi.org/10.24873/j.rpemd.2018.11.325 